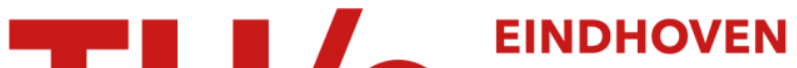 UNIVERSITY OF TECHNOLOGY
}

\section{Attenuation of propagating spin wave induced by layered nanostructures}

\section{Citation for published version (APA):}

Sekiguchi, K., Vader, T. N., Yamada, K., Fukami, S., Ishiwata, N., Seo, S. M., Lee, S. W., Lee, K. J., \& Ono, T. (2012). Attenuation of propagating spin wave induced by layered nanostructures. Applied Physics Letters, 100(13), 132411-1/3. [132411]. https://doi.org/10.1063/1.3699020

DOI:

$10.1063 / 1.3699020$

Document status and date:

Published: 01/01/2012

\section{Document Version:}

Publisher's PDF, also known as Version of Record (includes final page, issue and volume numbers)

\section{Please check the document version of this publication:}

- A submitted manuscript is the version of the article upon submission and before peer-review. There can be important differences between the submitted version and the official published version of record. People interested in the research are advised to contact the author for the final version of the publication, or visit the $\mathrm{DOI}$ to the publisher's website.

- The final author version and the galley proof are versions of the publication after peer review.

- The final published version features the final layout of the paper including the volume, issue and page numbers.

Link to publication

\section{General rights}

Copyright and moral rights for the publications made accessible in the public portal are retained by the authors and/or other copyright owners and it is a condition of accessing publications that users recognise and abide by the legal requirements associated with these rights.

- Users may download and print one copy of any publication from the public portal for the purpose of private study or research.

- You may not further distribute the material or use it for any profit-making activity or commercial gain

- You may freely distribute the URL identifying the publication in the public portal.

If the publication is distributed under the terms of Article 25fa of the Dutch Copyright Act, indicated by the "Taverne" license above, please follow below link for the End User Agreement:

www.tue.nl/taverne

Take down policy

If you believe that this document breaches copyright please contact us at:

openaccess@tue.nl

providing details and we will investigate your claim. 


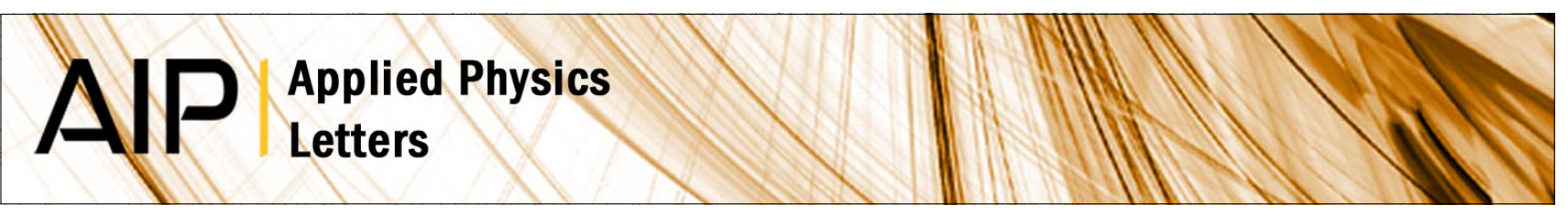

Attenuation of propagating spin wave induced by layered nanostructures

K. Sekiguchi, T. N. Vader, K. Yamada, S. Fukami, N. Ishiwata et al.

Citation: Appl. Phys. Lett. 100, 132411 (2012); doi: 10.1063/1.3699020

View online: http://dx.doi.org/10.1063/1.3699020

View Table of Contents: http://apl.aip.org/resource/1/APPLAB/v100/i13

Published by the AIP Publishing LLC.

Additional information on Appl. Phys. Lett.

Journal Homepage: http://apl.aip.org/

Journal Information: http://apl.aip.org/about/about_the_journal

Top downloads: http://apl.aip.org/features/most_downloaded

Information for Authors: http://apl.aip.org/authors

\section{ADVERTISEMENT}
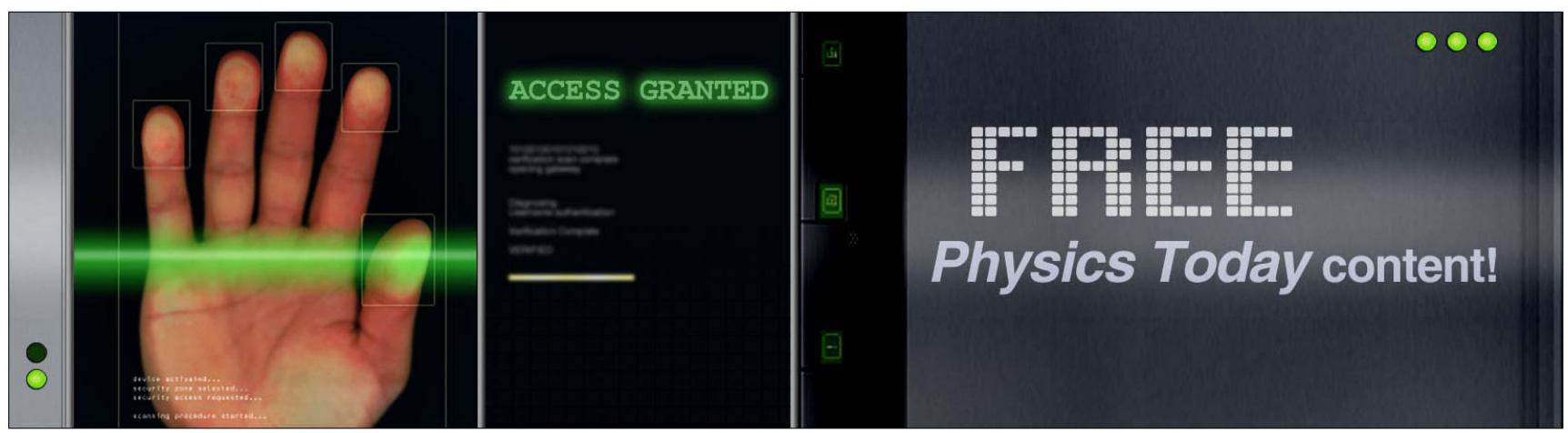


\title{
Attenuation of propagating spin wave induced by layered nanostructures
}

\author{
K. Sekiguchi, ${ }^{1}$ T. N. Vader, ${ }^{2}$ K. Yamada, ${ }^{1}$ S. Fukami, ${ }^{3}$ N. Ishiwata,${ }^{3}$ S. M. Seo, ${ }^{4}$ S. W. Lee, ${ }^{4}$ \\ K. J. Lee, ${ }^{4}$ and T. Ono ${ }^{1}$ \\ ${ }^{1}$ Institute for Chemical Research, Kyoto University, Uji 611-0011, Japan \\ ${ }^{2}$ Department of Applied Physics, Center for NanoMaterials and COBRA Research Institute, \\ Eindhoven University of Technology, P.O. Box 513, Eindhoven 5600MB, The Netherlands \\ ${ }^{3}$ NEC Corporation, 1120 Shimokuzawa, Sagamihara 252-5298, Japan \\ ${ }^{4}$ Department of Materials Science and Engineering, Korea University, Seoul 136-701, Korea
}

(Received 28 August 2011; accepted 11 March 2012; published online 30 March 2012)

\begin{abstract}
Spin wave attenuation in the layered $[\mathrm{FeNi} / \mathrm{Pt}]_{6} / \mathrm{FeNi}$ thin films was investigated by the time-domain electrical measurement. The spin-wave waveform was detected with an asymmetric coplanar strip transmission line, as an induced voltage flowing into a fast oscilloscope. We report that the amplitude of a spin-wave packet was systematically changed by controlling the thickness of a platinum layer, up to a maximum change of 50\%. The virtues of spin wave, ultrafast propagation velocity and non-reciprocal emission, are preserved in this manner. This means that the Pt layer can manipulate an arbitral power-level of spin-wave input signal (reliable attenuator). (C) 2012 American Institute of Physics. [http://dx.doi.org/10.1063/1.3699020]
\end{abstract}

Spintronic integrated circuits harnessing spin-wave propagation have been of great interest for signal processing in virtue of ultrafast propagation and low power consumption. ${ }^{1-3}$ The spin-wave logic gates have been recently demonstrated by using the Mach-Zehnder interferometer with yttrium iron garnet (YIG) waveguides. ${ }^{3}$ Since the YIG is not compatible with standard silicon integrated circuit (IC) technology, spin wave propagation in ICcompatible materials such as FeNi is of importance for the realization of integrated circuits. ${ }^{4-14}$ The magnetostatic surface wave (MSSW) in the FeNi film is the promising mode due to its high propagation velocity and a non-reciprocal character, which was also observed a long time ago in YIG films. ${ }^{3-5}$ As revealed in the previous letter, ${ }^{6}$ the nonreciprocal emission can be utilized for an initial input, since the non-reciprocal parameter $(\kappa)$ is unchanged even if a spin wave propagates a long distance. For the signal processing with spin wave, furthermore, the control of spin wave amplitude after the emission is of great importance.

In this Letter, we report an attenuation control method of spin-wave packet in FeNi/Pt-based thin films. The amplitude attenuation is caused by the dissipation of the magnetic energy into the environment and thus related to the intrinsic damping. By utilizing the ferromagnetic-normal metal (F-N) interface coupling, we achieved amplitude change of spin waves without influencing the main virtues of spin waves: ultrafast propagation, and non-reciprocal emission.

Spin-wave medium consist of $\left[\mathrm{Fe}_{17} \mathrm{Ni}_{83} / \mathrm{Pt}\right]_{6} / \mathrm{Fe}_{17} \mathrm{Ni}_{83}$ multilayer stacks grown by magnetron sputtering on intrinsic silicon substrates (see Table I) without annealing process. Here, the numbers in parentheses indicate the thickness of each layer in the unit of $\mathrm{nm}$. The volume content of Pt is controlled from $0 \%$ to $10 \%$, while the total thickness is kept constant at $35 \mathrm{~nm}$ (No. 1 to No. 5). The thickness of Pt layer $(t)$ in each medium was set to be much thinner than the spin diffusion length $\left(\lambda_{s d} \sim 15 \mathrm{~nm}\right)$, while those of FeNi are approximately the same as the spin diffusion length $\left(\lambda_{s d} \sim 5 \mathrm{~nm}\right)$. The saturation magnetization was proportional to the volume amount of FeNi layer, namely, the normalized magnetization curves of $\left[\mathrm{Fe}_{17} \mathrm{Ni}_{83} / \mathrm{Pt}\right]_{6} / \mathrm{Fe}_{17} \mathrm{Ni}_{83}$ medium are all identical, and a negligible magnetic anisotropy was observed (see inset of Fig. 1). ${ }^{15}$

The time-resolved propagating spin wave spectroscopy (PSWS) was carried out for the multilayer stacks patterned into $120 \mu \mathrm{m} \times 100 \mu \mathrm{m}$ stripes. Spin waves (MSSW) are excited and detected with a pair of asymmetric coplanar strip (ACPS) transmission lines placed on the film (see Fig. 1), with applying the external magnetic field $H_{\text {ext }} \sim 100$ Oe parallel to the ACPS. A voltage pulse launched into the excitation ACPS generates a spin-wave packet, which induces a voltage on the detection ACPS connected to a $20 \mathrm{GHz}$ sampling oscilloscope. The detail geometry of ACPS and experimental method are the same as reported in the previous letters. ${ }^{6,7}$ Spin wave wavevector $k \sim 0.5 \mu \mathrm{m}^{-1}$ is determined by the ACPS geometry, which corresponds to the resonant frequency of approximately $\omega / 2 \pi \sim 3.6 \mathrm{GHz}$. The spin wave frequencies were not changed even if we changed the Pt content. Experimentally, due to the mutual configuration between magnetization $M$ and wave vector $k$, the spin-wave packet can be measured by four different excitation configurations: $(M, k),(-M, k),(M,-k),(-M,-k)$, where the direction of $M$ is set by the external in-plane field, $H_{\text {ext }}$.

Figure 2(a) represents the time-resolved waveforms for the patterned media with different contents of $\mathrm{Pt}(0 \%, 2 \%$, $5 \%$, and $10 \%$ ). With increasing the content of Pt, the packet

TABLE I. List of FeNi-based medium.

\begin{tabular}{lcc}
\hline \hline Film no. & Layered structure $(\mathrm{nm})$ & Content of $\mathrm{Pt}(\%)$ \\
\hline 1 & $\mathrm{Fe}_{17} \mathrm{Ni}_{83}(35)$ & 0 \\
2 & {$[\mathrm{FeNi}(4.95) / \mathrm{Pt}(0.058)]_{6} / \mathrm{FeNi}(4.95)$} & 1 \\
3 & {$[\mathrm{FeNi}(4.90) / \mathrm{Pt}(0.117)]_{6} / \mathrm{FeNi}(4.90)$} & 2 \\
4 & {$[\mathrm{FeNi}(4.75) / \mathrm{Pt}(0.292)]_{6} / \mathrm{FeNi}(4.75)$} & 5 \\
5 & {$[\mathrm{FeNi}(4.50) / \mathrm{Pt}(0.583)]_{6} / \mathrm{FeNi}(4.50)$} & 10 \\
\hline \hline
\end{tabular}




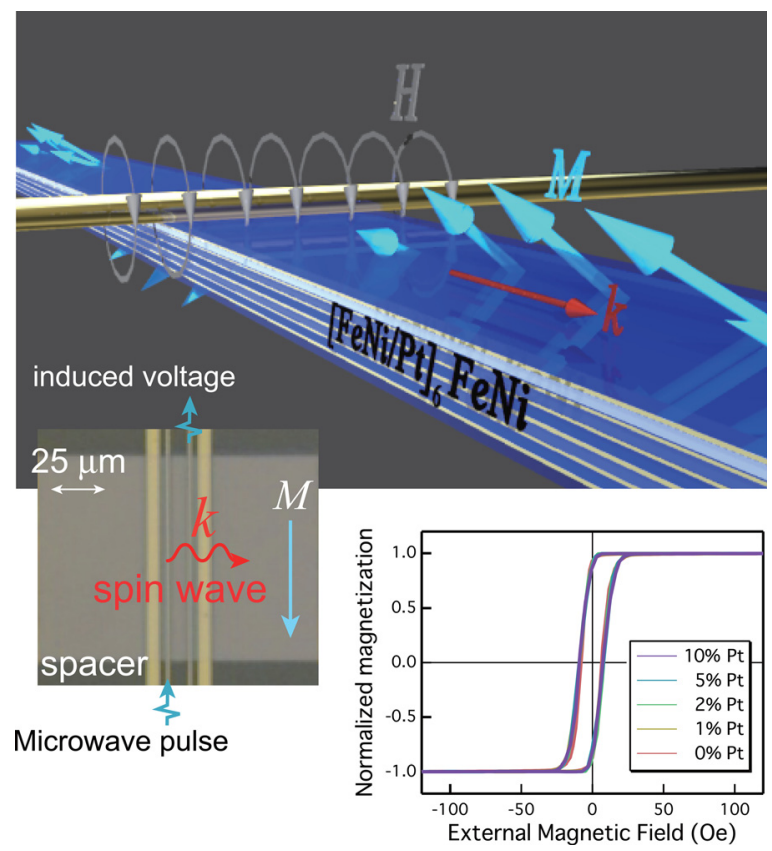

FIG. 1. Emission of spin-wave packet within FeNi-based films. A spinwave packet is excited by a local magnetic field and detected as an induced voltage. (Inset) Optical micrograph of the patterned sample with a pair of asymmetric coplanar strip (ACPS). The ACPSs are comprising a signal line $\left(w_{1}=3 \mu \mathrm{m}\right)$ and a ground line $\left(w_{2}=9 \mu \mathrm{m}\right)$ with a separation length $w_{3}=2 \mu \mathrm{m}$. (Inset) Normalized magnetization of the layered medium.

shows a distinct decay of amplitude without changing its envelope position. The envelopes of packets are well characterized by the Gaussian function $y=A \exp \left[-\left(\frac{t-t_{0}}{\tau}\right)^{2}\right]$, where $A$ is the amplitude, $t_{0}$ is the center of packet, and $\tau$ is the decay time.

In Figs. 2(b) and 2(c), the $A$ and $t_{0}$ are plotted as a function of the propagation distance. As clearly seen, the decay ratio increases with increasing the content of Pt (Fig. 2(b)), while the center position of the spin wave packet does not depend on the Pt content (Fig. 2(c)). The spin wave attenuation length $(\Lambda)$ is determined by the exponential fitting using the formula $A \exp (-x / \Lambda)$, and the group velocity $\left(v_{g}\right)$ by the linear slope of the delay. The $\Lambda$ and $v_{g}$ for all the excitation configurations are deduced and plotted as a function of $\mathrm{Pt}$ content. With increasing the Pt content from $0 \%$ to $10 \%$, the attenuation length $\Lambda$ is systematically decreased from $13 \mu \mathrm{m}$ to $6.5 \mu \mathrm{m}$, showing $50 \%$ change of amplitude [see Fig. 2(d)]. The group velocity, on the other hand, is approximately constant of $11.7 \mathrm{~km} / \mathrm{s}$ [see Fig. 2(e)]. This means that the Pt layer can change spin wave attenuation with preserving the ultrafast propagating velocity.

Note that the attenuation of the spin wave is directly connected with the damping parameter of the system. We can estimate the effective damping parameter from the attenuation length $\Lambda$. As shown in Fig. 3(a), a damping parameter is deduced to be 0.01 for the FeNi film (0\%), showing a good agreement with reported damping $\alpha_{0} \cdot{ }^{16-18}$ The effective damping slightly increases in the range of $0-2 \%$ Pt content, while it increases rapidly if the Pt content exceeds $2 \%$.

The enhancement of Gilbert damping would be caused by two reasons. It is known that the damping of FeNi films is enhanced when it is attached by a heavy metal like $\mathrm{Pt},{ }^{19,20}$ (a)
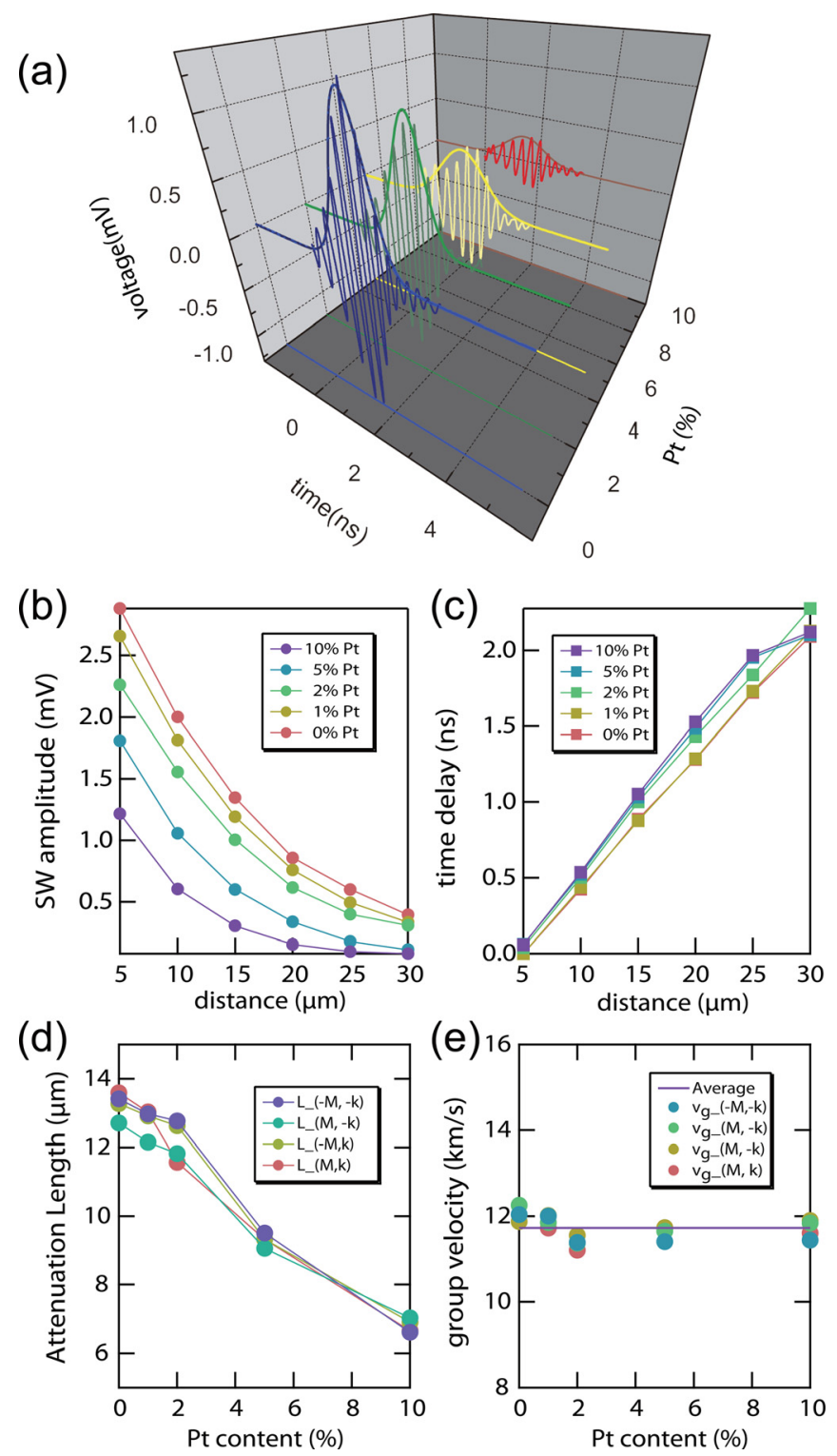

FIG. 2. (a) Time-resolved waveforms of a propagating spin-wave packet excited in FeNi-based films as a function of Pt content. The spin wave is excited with $(M, k)$ configuration and detected at the propagating distance of $15 \mu \mathrm{m}$. (b) Spin wave amplitudes and (c) center position with different gap distances, exhibiting an exponential decay and a linear increase, respectively. (d) Spin wave attenuation length and (e) group velocity for all excitation configurations.

caused by the spin pumping mechanism. ${ }^{21}$ However, it would be uneasy to directly apply this spin pumping mechanism to our experiment since the Pt layers are extremely thin. Another possible reason of the enhanced damping is that the Pt would act as a dopant into the FeNi films. It is consistent with previous studies ${ }^{22,23}$ where heavy-metal dopants in FeNi can increase the damping.

Finally, we discuss the non-reciprocity characterized by the parameter: $\kappa(M) \equiv A_{-k, M} / A_{k, M}$ and $\kappa(-M) \equiv A_{k,-M} /$ $A_{-k,-M} .{ }^{6}$ As shown in Fig. 3(b), in the range of $0 \%-2 \%$, the $\kappa$ shows gradual decrease from 0.67 , showing $4.5 \%$ change. This detail mechanism is left to be elucidated; however, the non-reciprocal parameter is approximately found to be constant $\langle\kappa\rangle=0.62$ if the Pt content exceeds $2 \%$. This average value agrees to the previous report, meaning the $\kappa$ is only determined by the geometry of ACPS. 

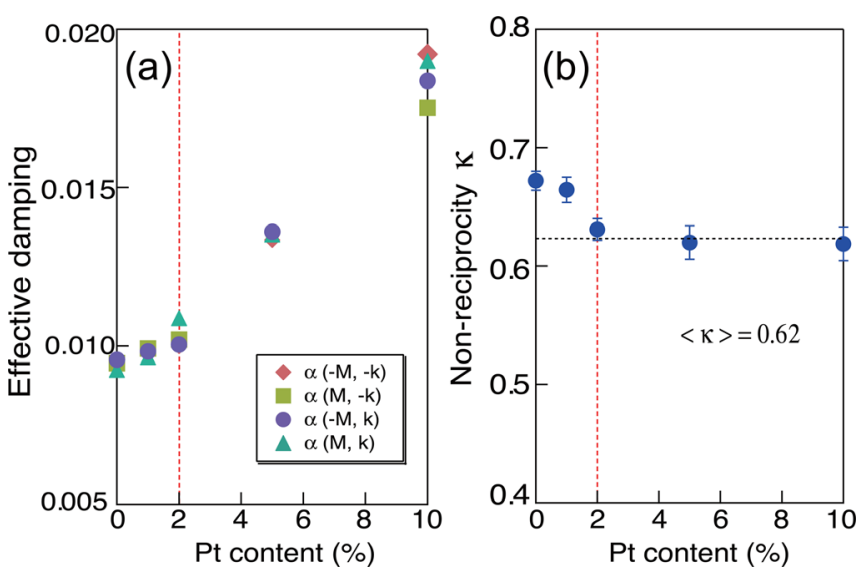

FIG. 3. (a) Effective damping parameter as a function of Pt content. (b) Non-reciprocal parameter $(\kappa)$ as a function of Pt content. The $\kappa(M)$ and $\kappa(-M)$ are observed to be equivalent for each medium. The $\kappa$ is averaged over the propagation distances except for the data at $30 \mu \mathrm{m}$, which introduces only a large error.

In conclusion, we have shown that we can systematically change the amplitude of spin-wave packet by inserting Pt layer, with preserving the ultrafast propagation velocity and the non-reciprocal emission. Thus, our findings lead to the spin-wave function as a signal attenuator for logical spinwave circuits.

K.S. acknowledges financial support from JST, PRESTO. T.O. acknowledges financial support from MEXT. K.J.L. acknowledges financial support from the National Research Foundation of Korea (NRF) grant funded by the Korea government (MEST) (Contract No. 2010-0023798).

${ }^{1}$ M. P. Kostylev, A. A. Serga, T. Schneider, B. Leven, and B. Hillebrands, Appl. Phys. Lett. 87, 153501 (2005).
${ }^{2}$ K. S. Lee and S. K. Kim, J. Appl. Phys. 104, 053909 (2008).

${ }^{3}$ T. Schneider, A. A. Serga, B. Leven, B. Hillebrands, R. L. Stamps, and M. P. Kostylev, Appl. Phys. Lett. 92, 022505 (2008).

${ }^{4}$ S. O. Demokritov, B. Hillebrands, and A. N. Slavin, Phys. Rep. 348, 441 (2001).

${ }^{5}$ D. D. Stancil, Theory of Magnetostatic Waves (Springer, 1993).

${ }^{6}$ K. Sekiguchi, K. Yamada, S. M. Seo, K. J. Lee, D. Chiba, K. Kobayashi, and T. Ono, Appl. Phys. Lett. 97, 022508 (2010).

${ }^{7}$ K. Sekiguchi, K. Yamada, S.-M. Seo, K.-J. Lee, D. Chiba, K. Kobayashi, and T. Ono, Phys. Rev. Lett. 108, 017203 (2012).

${ }^{8}$ V. E. Demidov, S. Demokritov, K. Rott, P. Krzysteczko, and G. Reiss, Appl. Phys. Lett. 91, 252504 (2007).

${ }^{9}$ K. Perzlmaier, G. Woltersdorf, and C. H. Back, Phys. Rev. B 77, 054425 (2008).

${ }^{10}$ M. Bailleul, D. Olligs, and C. Fermon, Appl. Phys. Lett. 83, 972 (2003).

${ }^{11}$ M. Bailleul, D. Olligs, C. Fermon, and O. Demokritov, Europhys. Lett. 56, 741 (2001).

${ }^{12}$ P. K. Amiri, B. Rejaei, M. Vroubel, and Y. Zhuang, Appl. Phys. Lett. 91, 062502 (2007).

${ }^{13}$ V. E. Demidov, M. P. Kostylev, K. Rott, P. Krzystechzko, G. Reiss, and S. O. Demokritov, Appl. Phys. Lett. 95, 112509 (2009).

${ }^{14}$ M. Covington, T. M. Crawford, and G. J. Parker, Phys. Rev. Lett. 89, 237202 (2002).

${ }^{15}$ The magnetization curve was clearly changed if we used an annealing process, and spin wave has never been excited. The annealing caused a strong affection on the layered magnetic state.

${ }^{16}$ S. Mizukami, Y. Ando, and T. Miyazaki, Jpn. J. Appl. Phys. 40, 580 (2001).

${ }^{17}$ N. Inaba, H. Asanuma, S. Igarashi, S. Mori, F. Kirino, K. Koike, and H. Morita, IEEE Trans. Magn. 40, 2372 (2006).

${ }^{18}$ H. M. Olson, P Krivosik, K. Srinivasan, and C. E. Patton, J. Appl. Phys. 102, 023904 (2007).

${ }^{19}$ S. Mizukami, Y. Ando, and T. Miyazaki, J. Magn. Magn. Mat. 226, 1640 (2001).

${ }^{20}$ S. Ingvarsson, L. Ritchie, X. Y. Liu, G. Xiao, J. C. Slonczewski, P. L. Trouilloud, and R. H. Koch, Phys. Rev. B 66, 214416 (2002).

${ }^{21}$ Y. Tserkovnyak, A. Brataas, and G. E. W. Bauer, Phys. Rev. Lett. 88, 117601 (2002).

${ }^{22}$ G. Woltersdorf, M. Kiessling, G. Meyer, J.-U. Thiele, and C. H. Back, Phys. Rev. Lett. 102, 257602 (2009).

${ }^{23}$ R. L. Thomas, M. Zhu, C. L. Dennis, V. Mistra, and R. D. McMichael, J. Appl. Phys. 110, 033902 (2011). 